\title{
Shear resistance behaviour of geogrid-confined RC elements under static and cyclic loading
}

\author{
R. Siva Chidambaram ${ }^{1, *}$ and Pankaj Agarwal ${ }^{2}$ \\ ${ }^{1}$ CSIR-Central Building Research Institute, Roorkee 247 667, India \\ ${ }^{2}$ Department of Earthquake Engineering, Indian Institute of Technology Roorkee, Roorkee 247 667, India
}

\begin{abstract}
The present experimental work is concerned with the application of geogrid as partial transverse reinforcement in reinforced concrete beams and exterior beamcolumn joints. The composite advantages of steel fibre with minimum percentage and geogrid in resisting the shear force of beam and beam-column joint specimens with increased stirrup spacing under static and reverse cyclic loading are studied in detail. The loaddeflection curve, hysteretic loop, post-elastic strength and stiffness degradation, energy dissipation, failure pattern and damage tolerance capacity are the parameters used in this study to evaluate the performance of adopted new confinement technique. The improved shear carrying capacity with better inelastic response represents the advantages of the geogrid in RC structural elements. Also the enhanced energy dissipation and better damage tolerance of composite action provided by geogrid and steel fibre authenticate the use of synergetic effect in resisting the shear force in RC beams and beam-column joints.
\end{abstract}

Keywords: Cyclic behaviour, damping, damage tolerance, geogrid confinement, hysteretic behaviour, moment rotation, SFRC.

WHEN structures are subjected to severe loads such as earthquake, wind and blast loads, the shear carrying capacity of reinforced concrete (RC) elements reduces due to inadequate transverse reinforcement. Inappropriate shear reinforcement detailing and corrosion of transverse reinforcement lead to catastrophic failure. The conventional ways of improving shear carrying capacity are, using higher compressive strength concrete, adequately spaced shear reinforcement (stirrups) and increasing the cross-sectional area of members. The closely spaced confined reinforcement in the hinge regions improves the concrete shear carrying capacity and alters the failure mode from brittle to ductile failure. In particular, the conventional way of improving the shear resistance of the plastic hinge region of members is partially achieved to get the desired strength and ductile behaviour but, still beam-column joints fail in shear under severe earthquake loads. Simultaneously, congestion due to confined rein-

*For correspondence. (e-mail: krsinelastic@gmail.com) forcement leads to construction difficulty. The limited improvement in the shear behaviour by the confining reinforcement opens up other alternatives. The high tensile confining materials and high performance materials can be used to improve the shear resistance of concrete near the hinge regions. One of the options under this class is the use of geogrid as an additional confining reinforcement with or without steel fibre reinforced concrete (SFRC).

Geogrid can be moulded into any shape due to its flexible nature. Geogrids are widely used in confining and reinforcing the soil to add tensile strength and deformation properties. They are also used to increase the stiffness, bearing capacity of the base course materials and prevent lateral movement in asphalt-paved roads. The geogrid is made from different materials such as polypropylene, polyethylene and other polymers with external coating. The addition of randomly distributed steel fibre in concrete offers better tensile stress and strain characteristics. Numerous studies focusing on the influence of SFRC on the shear resistance capacity of RC Structural elements were carried out. The randomly distributed steel fibre in concrete increases the shear strength ${ }^{1}$. The use of SFRC in the beam column joint plastic hinge region eliminates the need for closely-spaced stirrups and improves the energy dissipation without compromise in shear resistance ${ }^{2}$. The fibre acts as a bridge across the cracks and hinders the crack growth which adds ductility to the structural element. The crack bridging action of steel fibre acts as secondary shear reinforcement in $\mathrm{RC}$ elements $^{3,4}$. ACI 544 also discusses the use of SFRC in structural elements and optimizing the usage of stirrups (spacing and area of cross sections of stirrups) ${ }^{5}$. The application of SFRC at the critical stress concentration joints in the components is the most successful method to avoid steel congestion. It improves the shear resistance of concrete elements with optimum spacing of stirrups with adequate cross sectional area, confines reinforcement and provides ductility. However, higher volume of steel fibre in SFRC leads to fibre segregation, voids and construction difficulty. Therefore, the efficiency and effectiveness of SFRC entirely depend on the percentage of steel fibres, aspect ratio, strength of fibres, dispersion and location, besides the stirrup ratio and the ductile behaviour $^{6,7}$. 


\section{Review of literature}

Experimental studies carried out so far, that focus on inelastic response of different beam-column joints using different reinforcement details suggest that the confinement in the joint hinge region mainly resists the shear forces, other than confining concrete ${ }^{8-10}$. The transverse confinement enhances joint performance and shear strength $^{11,12}$. It also enhances the bond behaviour, resists the longitudinal reinforcement slippage ${ }^{13}$ and enhances the plastic rotation capacity ${ }^{14}$. The ductile detailing recommended by codes of practise improves the shear resistance, but also leads to reinforcement congestion in the joint zone leading to construction difficulty in practice $e^{8,15}$. The joint shear behaviour can also be improved without special ductile detailing by using SFRC $^{16-19}$.

SFRC enables dissipation of energy significantly after cracking because of its fibre-bridging property and also eliminates closely spaced stirrups without compromising the flexural and shear capacity of structural elements ${ }^{20-23}$. The use of optimum numbers of steel fibres in concrete may alter the brittle shear failure into ductile shear failure $^{24,25}$. However, higher volume steel fibre leads to segregation of fibre and air entrainment ${ }^{26}$ and also affects the efficiency. The fibre orientation, anchorage capacity, aspect ratio and uneven dispersion plays a crucial role in the performance of SFRC ${ }^{5,21,27,28}$. Therefore, SFRC may not be an alternative to replace the conventional confinement. Also, estimating increase in shear strength due to SFRC is also difficult ${ }^{22}$.

Many studies have been carried out on the improvement of pavement-bearing capacity of strip foundation, crack reduction in asphalt overlays, while designing pavements. Few studies have focused on the use of geogrid in concrete as structural material. The effect of geogrid on concrete elements is studied and the confinement effect of geogrid under axial compression is examined $^{29-31}$. The authors observed better post-peak strain capacity and also examined the bonding behaviour of geogrid with concrete under bending. Sivakamasundari et $a l .{ }^{32}$ studied the effect of geogrid as partial confinement in $\mathrm{RC}$ elements and observed significant improvement in the strength, energy dissipation and displacement ductility. Yalciner et al. ${ }^{33}$ examined the effect of geogrid confinement and conventional shear reinforcement subjected to corrosion and concluded that the geogrids cannot provide adequate rigidity compared to conventional shear reinforcement and recommended special care when the geogrid is preferred for site work.

\section{Research significance}

The shear resistance of geogrid in reinforced concrete elements such as beams and beam-column joints as partial confining reinforcement necessitates detailed experimental study to authenticate its application in structural design. The existing experimental study on the influence of geogrid confinement paves way for further exploration. One study completely used geogrid as confining reinforcement and suggested not to use geogrid as confining reinforcement without using conventional steel stirrups. This study mainly focused on the shear resistance capacity of partial geogrid confinement with different stirrups ratio under static and cyclic loading. Also the composite effect of steel fibre and geogrid in resisting the shear force is explored.

\section{Experimental program}

The influence of geogrid as partial transverse reinforcement confinement in RC beams and beam column joints under static and cyclic loading is examined.

\section{Materials specification}

The ordinary Portland cement (OPC) of grade 43, locally available river sand as fine aggregate, and coarse aggregate having $20 \mathrm{~mm}$ maximum size, with 0.45 watercement $(\mathrm{W} / \mathrm{C})$ ratio and $0.5 \%$ super-plasticizer for better workability were used in concrete with a mix proportion of $1: 1.45: 2.25$. The hooked end steel fibre of $35 \mathrm{~mm}$ length, $0.60 \mathrm{~mm}$ diameter, aspect ratio of 60 , and nominal tensile strength of $1100 \mathrm{MPa}$ was used to prepare SFRC. In order to equate the density of conventional concrete, slightly modified concrete mix proportion of $1: 1.40$ : 2.20 was used to prepare SFRC with $1 \%$ steel fibre. Fe500 grade reinforcements were used as longitudinal reinforcement and $\mathrm{Fe} 250 / \mathrm{Fe} 500$ grade reinforcements were used as stirrups. Uniaxial geogrid having an average tensile strength of $250 \mathrm{kN} / \mathrm{m}$ in the longitudinal direction (Figure $1 b$ ) and $30 \mathrm{kN} / \mathrm{m}$ in the transverse direction was used. The typical details of the geogrid used in this study are shown in Figure $1 c$.

\section{Static behaviour of RC beam specimens}

Six different types of RC beam specimens with modified stirrup ratio and geogrid confinement were used in this study. Three specimens were used for each type and the average of three was used in the discussion. The prime objective is to examine the shear resistance capacity of geogrid-confined RC beams with different stirrup spacings. SFRC was used with and without geogrid confinement to study the synergetic effect of SFRC and geogrid in improving the shear carrying capacity and inelastic behaviour. Table 1 presents the detailed configurations of $\mathrm{RC}$ beams and Figure 2 shows the typical details of the beam specimen. Two point monotonic loading under load 

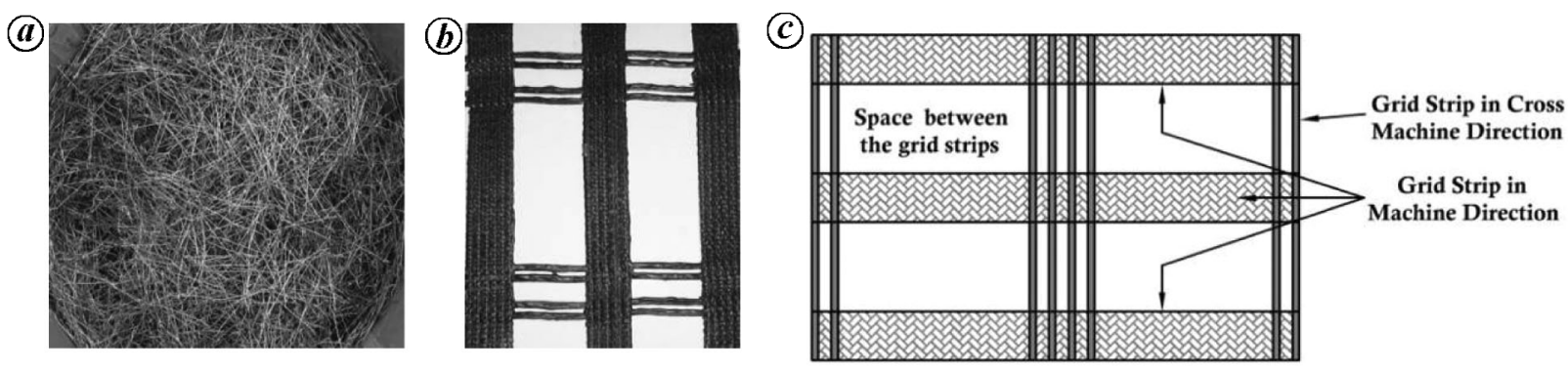

Figure 1. Typical details of geogrid and steel fibre. $\boldsymbol{a}$, Hooked end steel fibre. $\boldsymbol{b}$, Uni-axial geogrid. $\boldsymbol{c}$, Geogrid details.
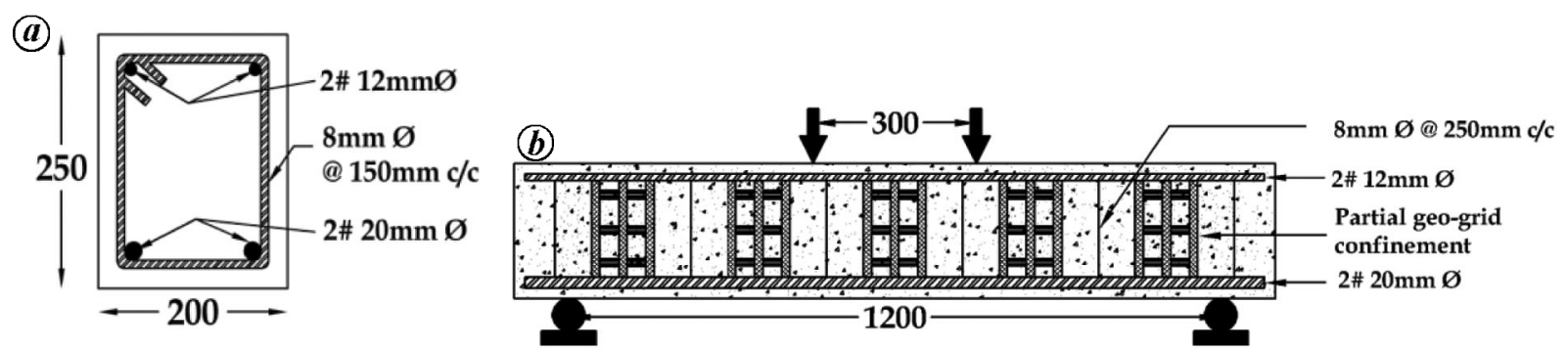

Figure 2. Reinforcement and cross section details of RC beams specimens. $\boldsymbol{a}$, Cross section; $\boldsymbol{b}$, Test setup.

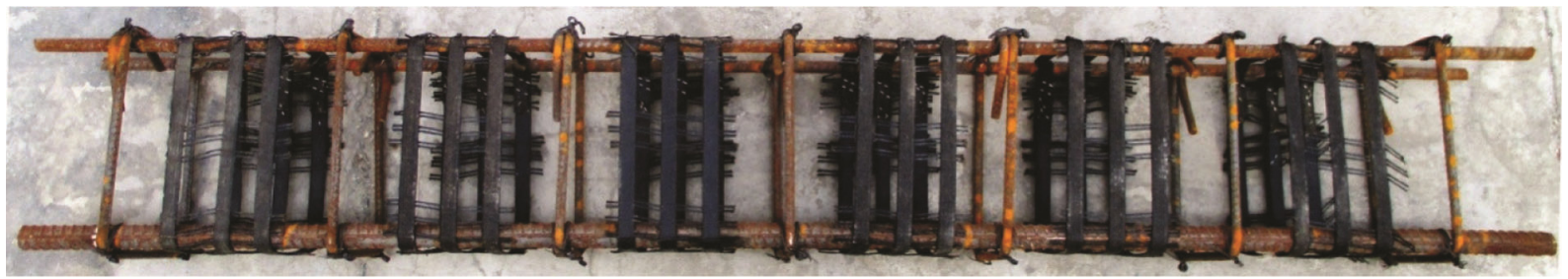

Figure 3. Typical geogrid confined specimen.

Table 1. Detailed configuration of RC beam specimens

\begin{tabular}{|c|c|c|c|c|c|c|}
\hline \multirow[b]{2}{*}{ Specimen id } & \multicolumn{2}{|c|}{$\begin{array}{l}\text { Longitudinal reinforcement } \\
\qquad(\mathrm{mm})\end{array}$} & \multicolumn{2}{|c|}{$\begin{array}{c}\text { Transverse } \\
\text { reinforcement (mm) }\end{array}$} & \multirow[b]{2}{*}{ Steel fibre $(\%)$} & \multirow[b]{2}{*}{ Description } \\
\hline & Top & Bottom & Size & Spacing & & \\
\hline GSB-1 & $2 \# 12 \varnothing$ & $2 \# 20 \varnothing$ & $8 \varnothing$ & 150 & - & Control beam \\
\hline GSB-2 & 2 \#12 Ø & $2 \# 20 \varnothing$ & $8 \varnothing$ & 200 & - & Geogrid confinement along with $200 \mathrm{~mm}$ stirrups spacing \\
\hline GSB-3 & 2 \#12 Ø & $2 \# 20 \varnothing$ & $8 \varnothing$ & 200 & 0.5 & \\
\hline GSB-4 & $2 \# 12 \varnothing$ & $2 \# 20 \varnothing$ & $8 \varnothing$ & 250 & - & Geogrid confinement along with $250 \mathrm{~mm}$ stirrups spacing \\
\hline GSB-5 & 2 \#12 Ø & $2 \# 20 \varnothing$ & $8 \varnothing$ & 250 & 0.5 & \\
\hline GSB-6 & 2 \#12 Ø & $2 \# 20 \varnothing$ & $8 \varnothing$ & 200 & 1.0 & SFRC $1 \%$ with $200 \mathrm{~mm}$ stirrups spacing \\
\hline
\end{tabular}

control with the rate of $50 \mathrm{~N} / \mathrm{s}$ was used and linear variable differential transducer (LVDT) was used to measure the mid-span deflection. Typical geogrid-confined specimen is shown in Figure 3.

\section{Load-deflection behaviour}

Table 2 summarizes the test results and Figure 4 shows the comparative load-deflection response of $\mathrm{RC}$ beam specimens. The lesser span to depth ratio with higher percentage of main reinforcement leads the specimens to fail in shear. The conventional specimen (GSB-1) exhibits sudden drop in load after peak as a result of shear crack widening. The domination of shear cracks greatly affects the post-elastic behaviour and hence GSB-1 has failed to show post-peak degradation. In geogrid-confined specimen, stirrup spacing plays a vital role in enhancing the confining effect. With a higher spacing between the stirrups, the geogrid confinement improves the confining effect and allows the specimen to deflect more ${ }^{7}$. Thus the specimen GSB-4 with geogrid confinement having higher stirrup spacing shows better load-carrying capacity than 
RESEARCH ARTICLES

Table 2. Test results of RC beam specimens

\begin{tabular}{|c|c|c|c|c|c|c|c|c|}
\hline \multirow[b]{2}{*}{ Specimen ID } & \multicolumn{2}{|c|}{ Yield stage } & \multicolumn{2}{|c|}{ Maximum stage } & \multicolumn{2}{|c|}{ Ultimate stage } & \multirow{2}{*}{$\begin{array}{l}\text { Ductility } \\
\text { factor }(\mu)\end{array}$} & \multirow{2}{*}{$\begin{array}{l}\text { Energy dissipation } \\
(\mathrm{kN})-\mathrm{mm}\end{array}$} \\
\hline & $P_{\mathrm{y}}(\mathrm{kN})$ & $\Delta_{y}(\mathrm{~mm})$ & $P_{m}(\mathrm{kN})$ & $\Delta_{m}(\mathrm{~mm})$ & $P_{u}(\mathrm{kN})$ & $\Delta_{u}(\mathrm{~mm})$ & & \\
\hline GSB-1 & 261.4 & 6.6 & 261 & 6.6 & 200 & 7.2 & 1.1 & 1090 \\
\hline GSB-2 & 235.9 & 6.2 & 235 & 6.2 & 165 & 10 & 1.6 & 1587 \\
\hline GSB-3 & 269.2 & 5.8 & 270 & 6.0 & 230 & 10.4 & 1.8 & 2040 \\
\hline GSB-4 & 270.2 & 6.3 & 273 & 6.7 & 230 & 8.2 & 1.3 & 1440 \\
\hline GSB-5 & 250.1 & 6.1 & 254 & 6.5 & 220 & 9.8 & 1.6 & 1757 \\
\hline GSB-6 & 280.5 & 6.1 & 281 & 6.5 & 220 & 9.6 & 1.6 & 1880 \\
\hline
\end{tabular}

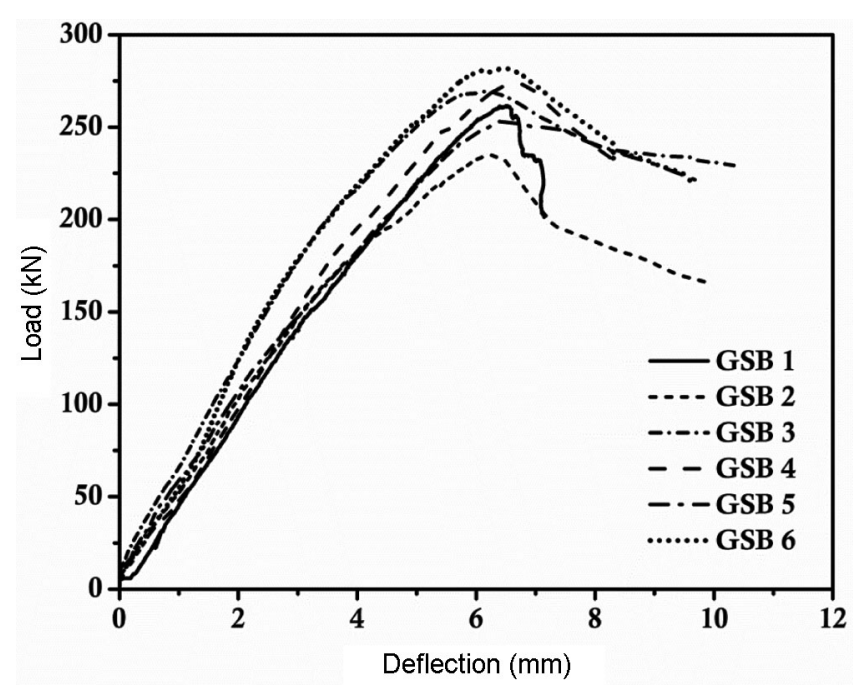

Figure 4. Load deflection curve of all type of RC beams.

the specimen GSB-2. The compressive strength of concrete used in GSB-2 is considerably less compared to the conventional specimen. Thus the peak load of specimen GSB-2 is slightly lesser than the control specimen GSB1. Both GSB-2 and GSB-4 exhibit considerable post-peak deformation compared to the control specimen. This proves that the geogrid confinement effectively improves the confinement effect and allows higher deformation. The addition of steel fibre in partial geogrid-confined specimen improves the load-carrying capacity and importantly the post-peak deflection. In general $0.5 \%$ steel fibre has less influence in improving the strength compared to higher volume steel fibre containing concrete specimens. In this study the specimen GSB-3 and GSB-5 show significant improvement in inelastic behaviour even with $0.5 \%$ steel fibre. The observed inelastic deformation is gradual and has $60 \%$ higher deflection than the control specimen GSB-1. The SFRC specimen GSB-6 shows improved initial stiffness but has failed to show better inelastic deformation. The result shows that the SFRC with $1 \%$ volume fibre in concrete reduces $25 \%$ of transverse reinforcement and $25 \%$ higher shear strength than the conventional technique. However, the rate of post-peak degradation is high compared to geogrid-confined specimen.

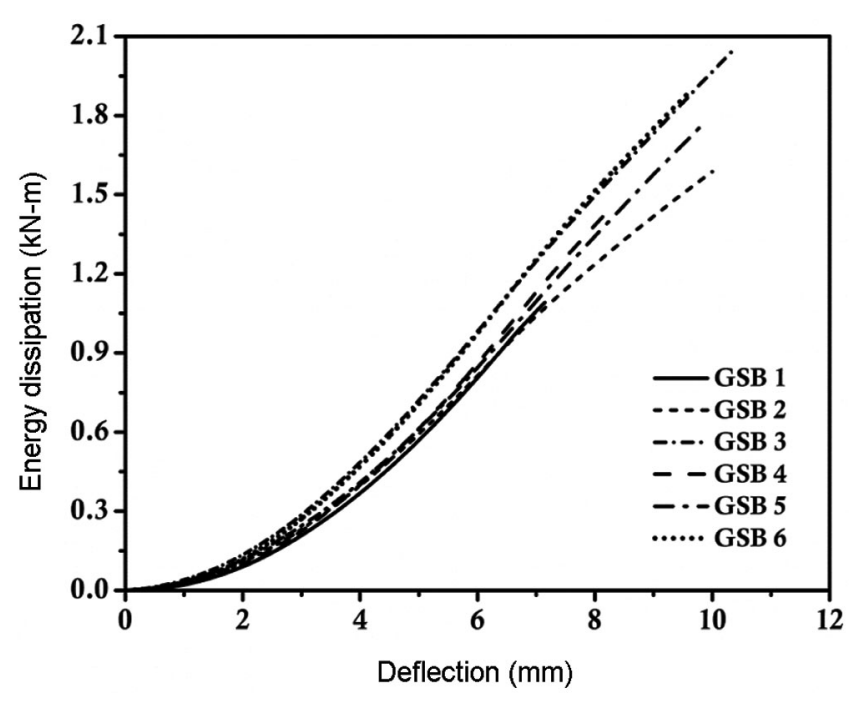

Figure 5. Energy dissipation of RC beams.

\section{Energy dissipation}

The energy dissipation capacity of structural elements indicates the ductility behaviour. The area beneath the load deflection curve estimates the energy dissipation. Figure 5 shows the estimated energy dissipation of tested specimens. Geogrid-confined specimens show considerable enhancement in energy dissipation compared to the conventional beam specimen (GSB-1). The specimen with SFRC and geogrid confinement shows two-fold increase in energy dissipation compared to the specimen without SFRC. It shows that the combined action works perfectly in resisting the shear force and effectively dissipates higher energy. The geogrid with higher spacing from stirrups GSB-4 and GSB-5 shows reduced energy dissipation compared to specimens GSB-2 and GSB-3. It unveils that the spacing between the stirrups and geogrid plays a crucial role in deciding the performance of the confinement. Grid confinement with higher stirrup spacing improves strength, whereas the specimen with lower stirrup spacing improves ductility. The addition of steel fibre in both the cases shows enhanced strength and ductility than the specimen without SFRC. The specimen with SFRC GSB-6 shows $72 \%$ higher energy dissipation 


\section{RESEARCH ARTICLES}

compared to the conventional specimen. This is considerably higher than the geogrid-confined specimen but is less compared to the specimen with geogrid and SFRC. The crack-bridging mechanism of steel fibre allows the specimen to absorb more energy compared to specimens without SFRC.

\section{Stiffness degradation}

The stiffness and strength degradation are calculated in terms of post-elastic strength degradation over yield strength $\left(F_{\mathrm{deg}} \%\right)$ and post-elastic stiffness degradation over yield stiffness $\left(K_{\mathrm{deg}} \%\right)$ according to eqs (1) and (2) to estimate the inelastic behaviour of all tested $\mathrm{RC}$ beam specimens.

$$
\begin{aligned}
& F_{\mathrm{deg}} \%=\left[1-\frac{\left(F-F_{y}\right)}{F_{y}}\right] \times 100, \\
& K_{\mathrm{deg}} \%=\left[1-\frac{\left(K-K_{y}\right)}{K_{y}}\right] \times 100 .
\end{aligned}
$$

where $F$ is the maximum load of each cycle, $\mathrm{kN}, F_{y}$ the yield load, $\mathrm{kN}, K$ the stiffness, $\mathrm{kN} / \mathrm{mm}, K_{y}$ is the yield stiffness, $\mathrm{kN} / \mathrm{mm}$.

Figure 6 shows the strength and stiffness degradation plot over post-elastic rotation. The early shear crack formation and brittle failure in specimen GSB-1 shows least performance in stiffness retention capacity. The degradation of beam specimen GSB-1 is nearly vertical with high rate of degradation; finally the specimen failed at 0.004 radian. The specimen with geogrid sustains the post-yield rotation up to 0.012 radian, which reflects the influence of grid confinement in post-elastic rotation. The rate of strength and stiffness degradation is less in beam

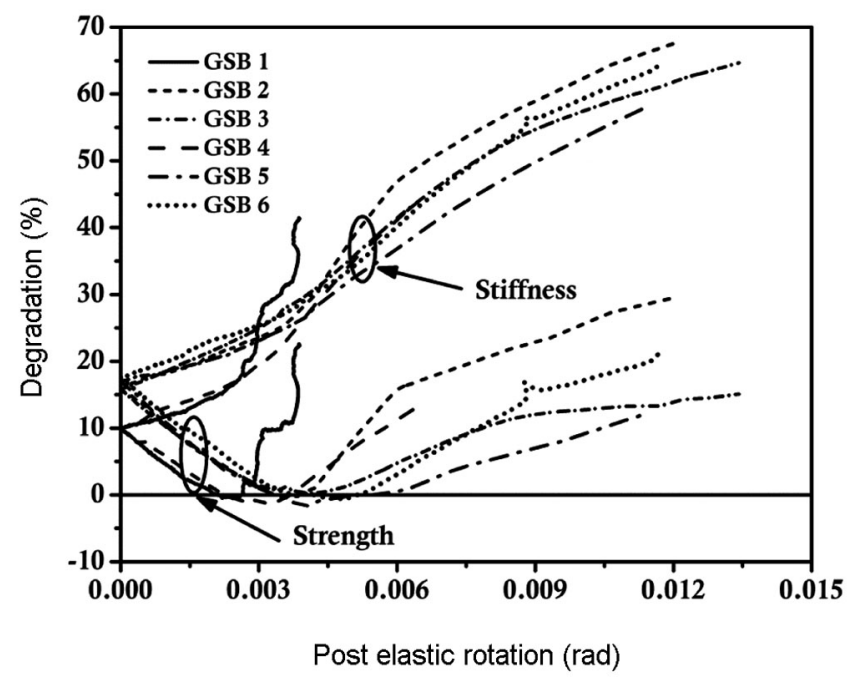

Figure 6. Strength and stiffness degradation. specimen GSB-3 and GSB-5 compared to specimen GSB2 and GSB-4 because of the presence of steel fibre. This clearly indicates that geogrid confinement even with higher spacing from stirrups shows better post-yield stiffness retention. The synergetic effect of steel fibres further enhances the performance of beam specimens.

\section{Crack pattern and failure analysis}

Figure 7 shows the crack pattern and failure mode of tested specimens. All beam specimens encounter shear failure as a result of low span to depth ratio. In the conventional specimen, flexural cracks were initiated in the mid-span during initial stage of loading. The occurrence of inclined cracks in the shear span led the specimens to fail in shear as depicted in Figure 7. In geogrid-confined beam specimen GSB-2 and specimen GSB-3 with steel fibres inclined cracks in the shear span region were observed and specimens failed in shear with one primary crack as shown in Figure $7 b$ and $c$. In specimen GSB-4 and GSB-5, vertical cracks were seen in the early stage of
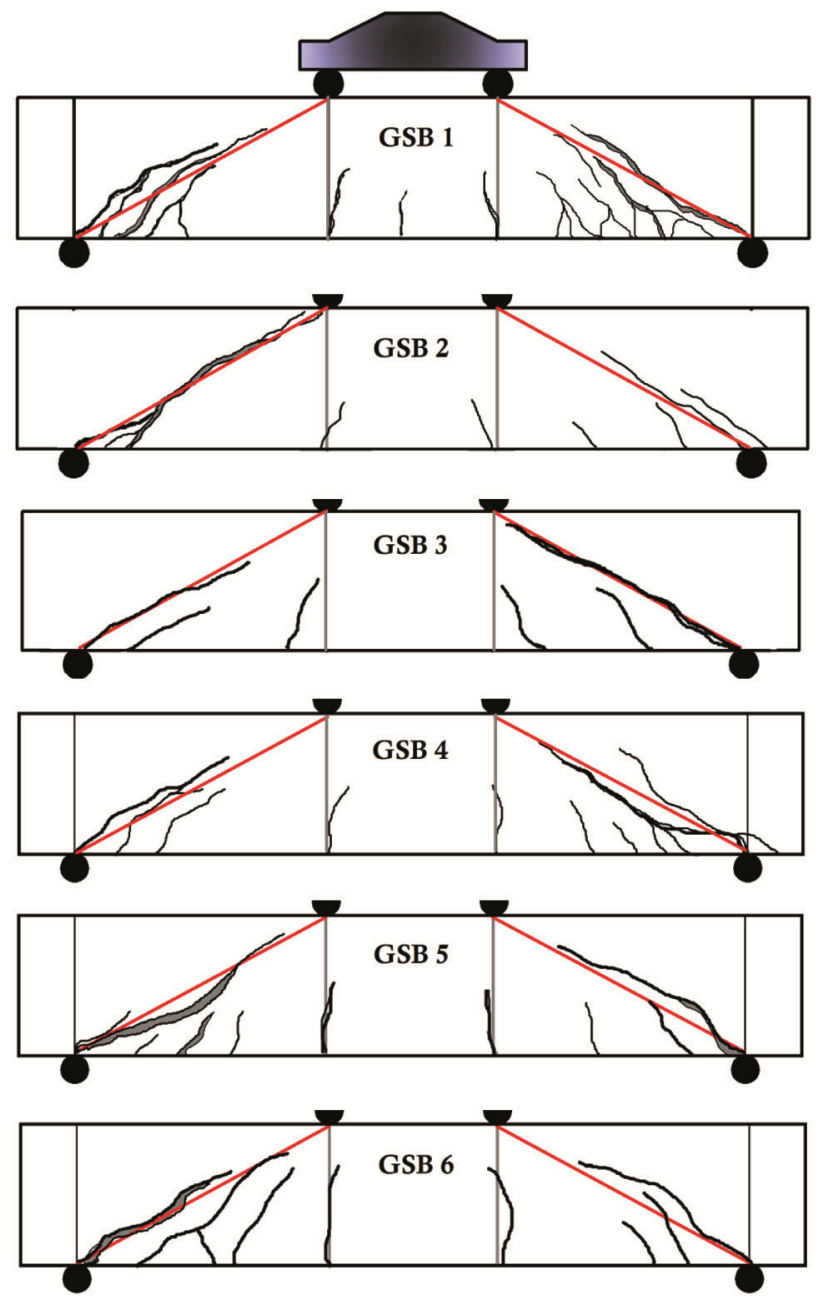

Figure 7. Crack pattern and failure mode of RC beam specimens. 
RESEARCH ARTICLES

Table 3. Configuration of exterior beam-column joint test specimens

\begin{tabular}{|c|c|c|c|c|}
\hline $\begin{array}{l}\text { Specimen } \\
\text { id }\end{array}$ & $\begin{array}{l}\text { Spacing of transverse reinforcement } \\
\qquad(\mathrm{mm})\end{array}$ & $\begin{array}{c}\text { Special } \\
\text { configuration }\end{array}$ & $\begin{array}{l}\text { Volume of steel } \\
\text { fibre }(\%)\end{array}$ & Description \\
\hline FEJ 1 & $100 \mathrm{~mm} \mathrm{C} / \mathrm{C}$ & $\times$ & $\times$ & $\times$ \\
\hline FEJ 2 & $\begin{array}{l}50 \mathrm{~mm} \mathrm{C} / \mathrm{C} \text { in hinge and } 100 \mathrm{~mm} \mathrm{C} / \mathrm{C} \\
\text { in other region }\end{array}$ & Seismic detailing & $\times$ & $\times$ \\
\hline FEJ 3 & $\begin{array}{l}200 \mathrm{~mm} \mathrm{C} / \mathrm{C} \text { in hinge and } 100 \mathrm{~mm} \mathrm{C} / \mathrm{C} \\
\text { in other region }\end{array}$ & $\begin{array}{l}\text { Geogrid confinement } \\
\text { in the hinge }\end{array}$ & $\times$ & Geogrid confinement in the hinge \\
\hline FEJ 4 & $\begin{array}{l}200 \mathrm{~mm} \mathrm{C} / \mathrm{C} \text { in hinge and } 100 \mathrm{~mm} \mathrm{C} / \\
\mathrm{C} \text { in other region }\end{array}$ & $\begin{array}{l}\text { Geogrid confinement } \\
\text { in the hinge. }\end{array}$ & $1 \%$ & Geogrid confinement + SFRC \\
\hline
\end{tabular}
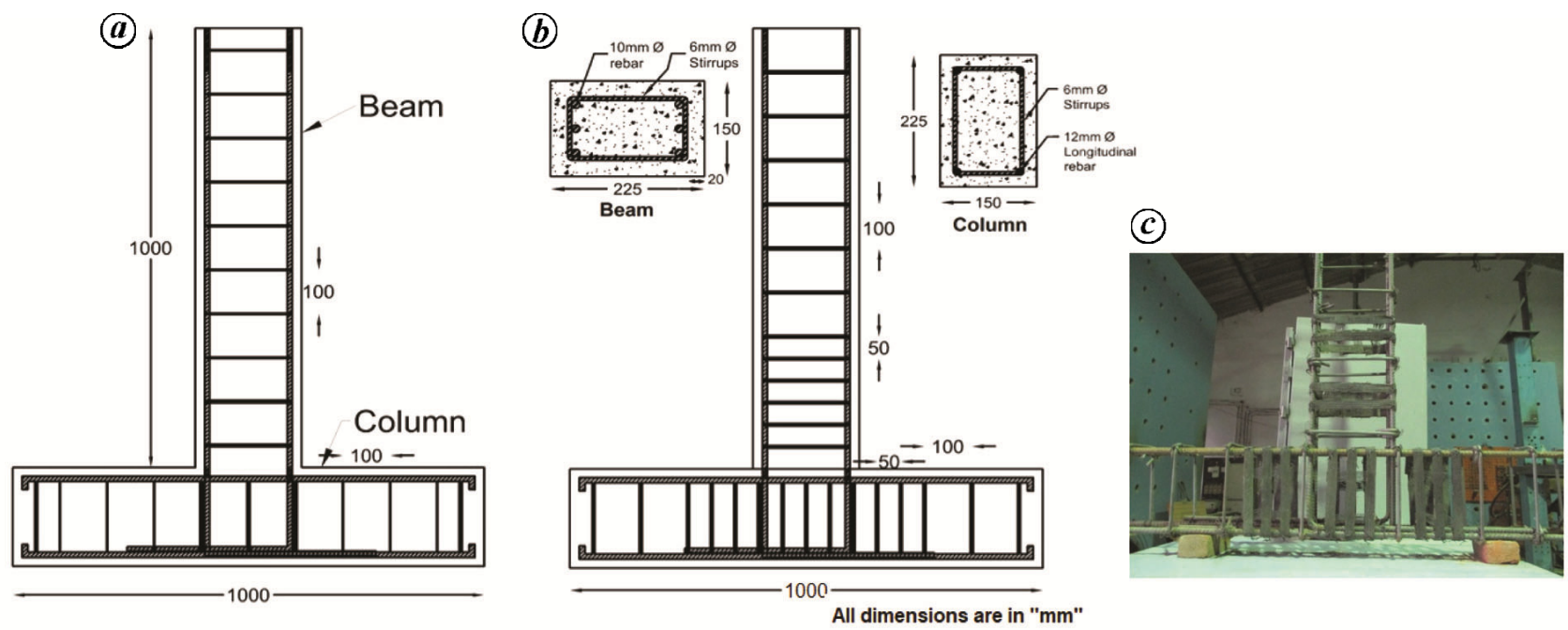

Figure 8. Beam-column joint reinforcement detailing of (a) FEJ 1, (b) FEJ 2 and (c) FEJ 3.

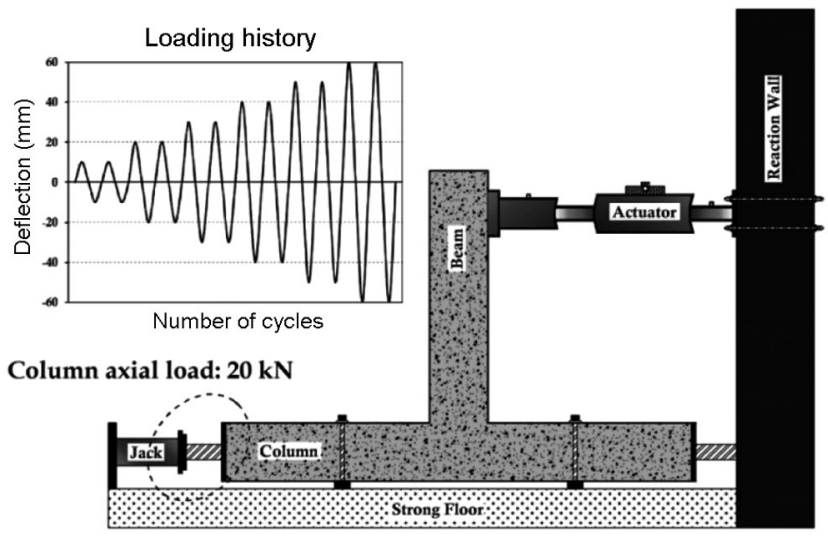

Figure 9. Experimental test setup of beam-column joint.

loading at the mid-span region; later inclined cracks developed in the shear span as shown in Figure $7 d$ and $e$. The crack pattern of beam specimens GSB-4 and GSB-5 shows that higher stirrup spacing allows the geogrid to perform better than closer spacing in multiple fine crack formations. The addition of steel fibre improves the damage-tolerance capacity of beam specimens.

\section{Cyclic behaviour of RC exterior beam-column joint specimens}

Exterior beam-column joint specimens with different stirrup ratios were cast and tested under sinusoidal loading under displacement control. The complete details of these specimens are given in Table 3. In this test sequence, four specimens were tested. Among them, FEJ 1 is the control specimen with uniform stirrup spacing and FEJ 2 is another control specimen with ductile detailing. The specimen FEJ 3 had geogrid confinement in the hinge region with $200 \mathrm{~mm}$ stirrup spacing as depicted in Figure $8 c$. In specimens FEJ 3 and FEJ 4 the reinforcement details and grid confinement are the same but, SFRC was used in the hinge region. Typical reinforcement details are shown in Figure 8. In cyclic testing of beam-column joint specimens, beam portion was kept $90^{\circ}$ vertical and the column was kept in the horizontal position held against the strong floor. Both ends of the column were supported using hydraulic jacks to apply axial load as shown in Figure 9. This test setup restricts the column's horizontal movement and supports moment free rotation. As the study mainly focuses on the shear behaviour of the joint through beam rotation, the column is 

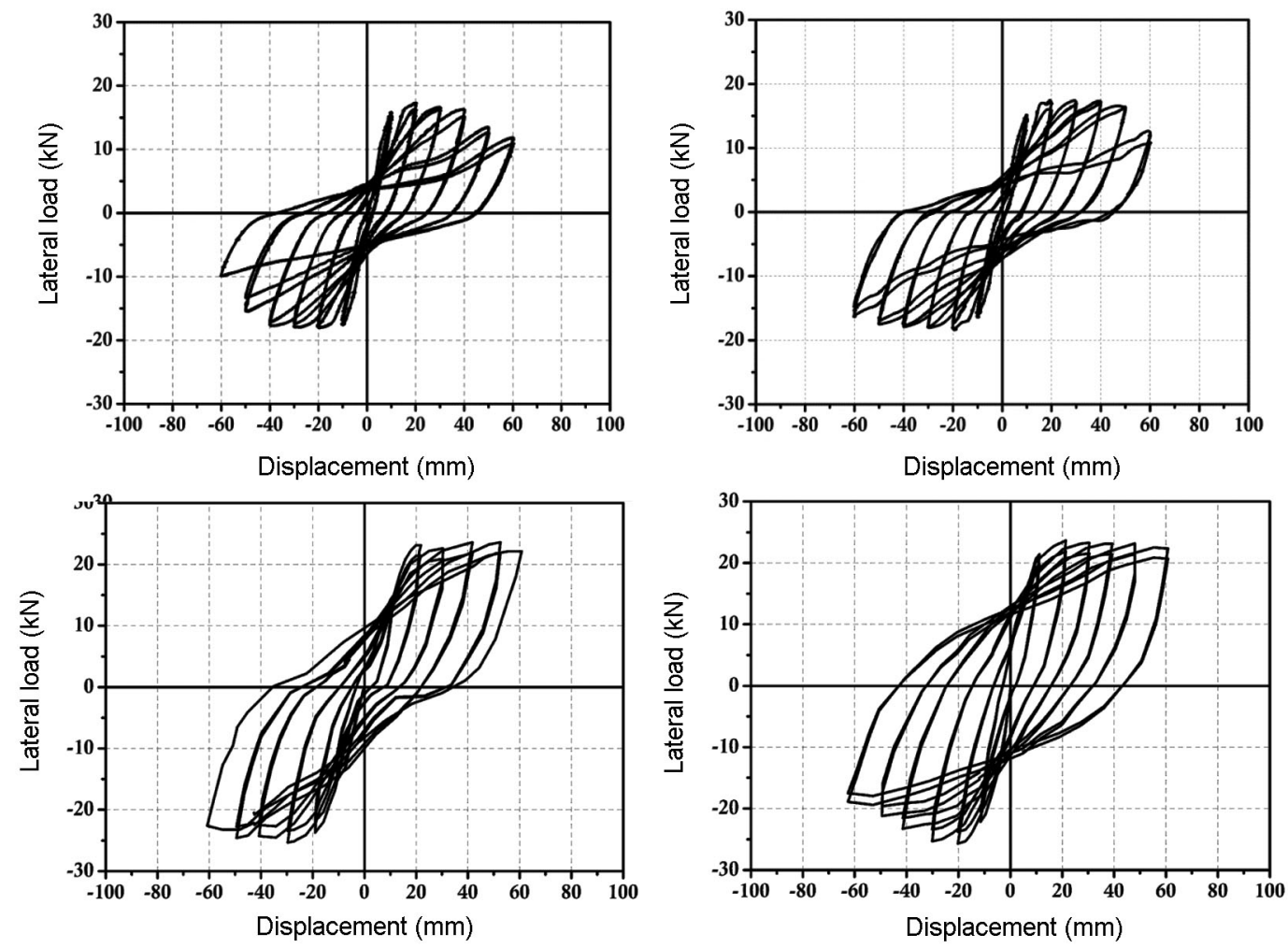

Figure 10. Hysteresis loop of exterior beam-column joint specimens.

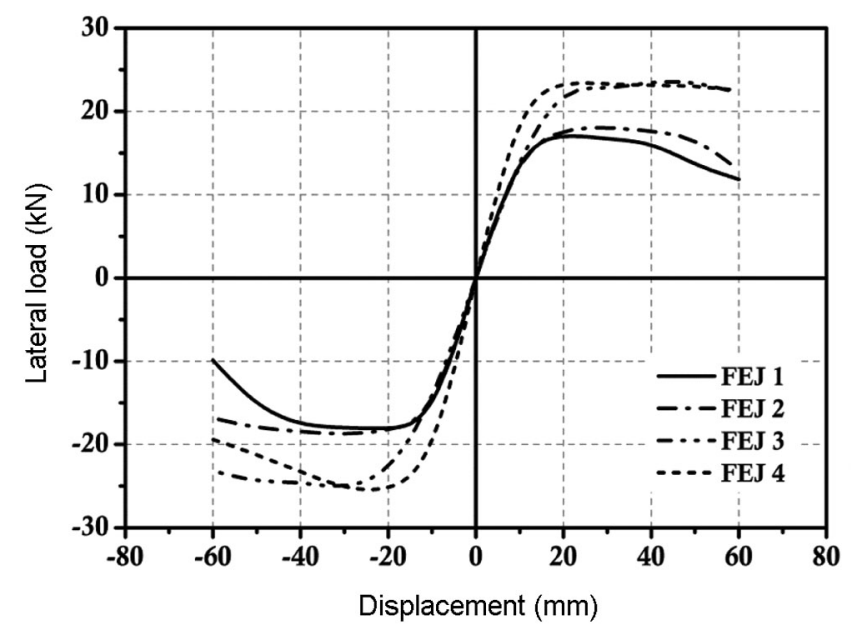

Figure 11. Load deflection envelope curve.

under fixed condition. The joints were tested under displacement-controlled hydraulic actuator. The reverse cyclic loading was applied in displacement control at a low frequency as depicted in Figure 9. The loading was increased gradually from $10 \mathrm{~mm}$ till the occurrence of failure with an interval of $10 \mathrm{~mm}$ for acquiring the inelastic performance behaviour of the joint. All the joint specimens were tested till failure and the corresponding load deformation response was acquired with the help of an inbuilt data acquisition system.

\section{Hysteresis behaviour}

Figure 10 shows the hysteretic curve of each joint specimen. The applied lateral force is resisted by the reinforced concrete in specimen FEJ 1 whereas in FEJ 2 it is resisted by the critical confinement and reinforced concrete. The difference can be understood from the hysteretic curve of FEJ 1 and FEJ 2 . In both the specimens, the peak load is attained at $20 \mathrm{~mm}$ deflection. The post-peak degradation starts after $40 \mathrm{~mm}$ deflection in FEJ 1 whereas it is $50 \mathrm{~mm}$ with lesser rate of degradation in FEJ 2. It shows the role of critical confinement in the joint plastic hinge region. The specimen FEJ 3 shows $30 \%$ higher load carrying capacity and better inelastic deformation than FEJ 1 and FEJ 2. Although the specimen encounters shear cracks in the joint, the confining effect of grid and transverse reinforcement restricts rebar slip and improves the post-yield strength and deformation capacity. Figure 10 shows that the area within the loop of FEJ 3 is larger than FEJ 1 and FEJ 2, which results in better energy dissipation ability. The cyclic performance is elevated with the use of steel fibre in specimen FEJ 4. The lateral load resistance capacity is equal to FEJ 3 but the loop area is larger than FEJ 3, which shows the effectiveness of steel fibre in increasing the shear resistance due to higher energy dissipation. Nearly $45 \%$ and $20 \%$ load drop are observed at $60 \mathrm{~mm}$ deflection with specimen FEJ 1 and FEJ 2 respectively. The hysteretic curve 

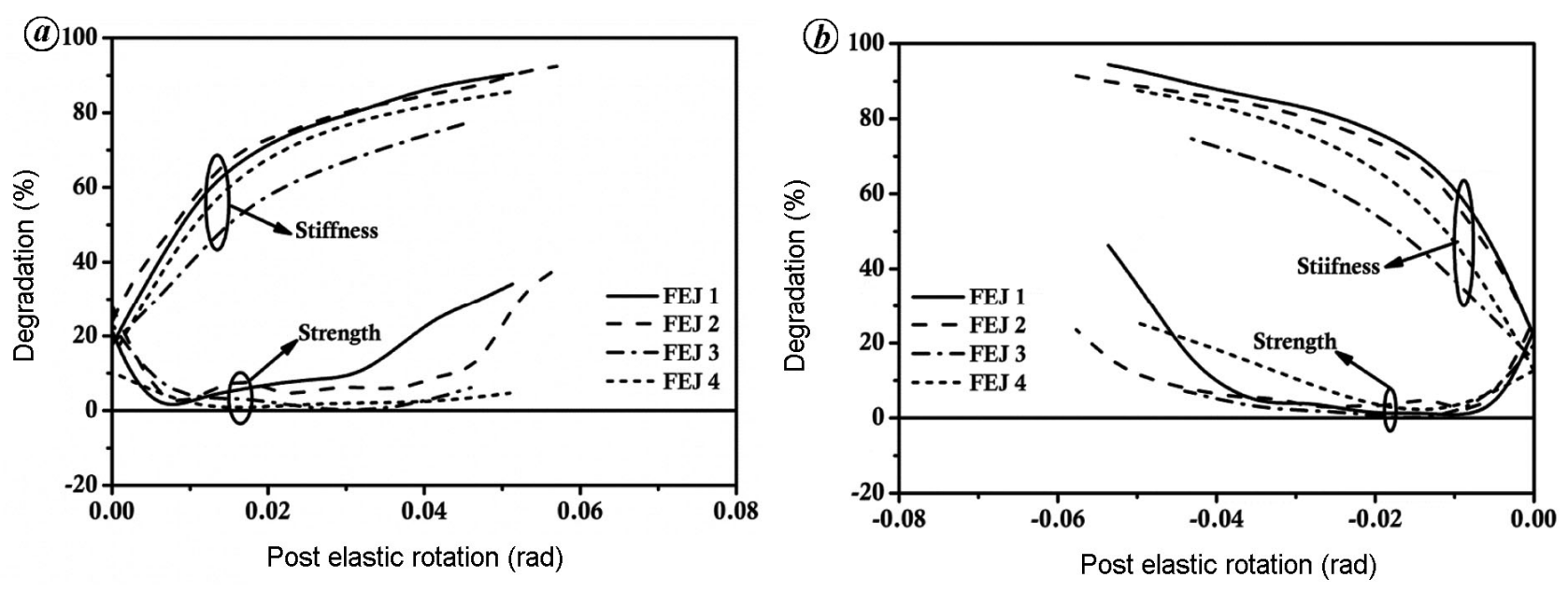

Figure 12. Strength and stiffness degradation of joint specimens. $\boldsymbol{a}$, Pushing; $\boldsymbol{b}$, Pulling direction.

of specimens FEJ 3 and FEJ 4 has no evidence of load drop at $60 \mathrm{~mm}$ deflection, and also the post yield behaviour is consistent until failure occurs.

\section{Envelope curve and stiffness degradation}

The envelope curve clearly demonstrates the enhanced load carrying capacity and post-peak deformation of specimens with geogrid confinement than conventionally confined specimens. The yield strength of geogridconfined specimens is $30 \%$ higher than the conventional specimens. Figure 11 shows the initiation of load drop after $40 \mathrm{~mm}$ deflection with conventional specimens FEJ 1 and FEJ 2, whereas there is no evidence of load drop at $40 \mathrm{~mm}$ deflection with grid-confined specimens FEJ 3 and FEJ 4. The tangent of the curve shows that there is huge difference in initial and yield stiffness between the specimen with and without steel fibre. The crack bridging mechanism of steel fibre restricts the early crack formation and its growth during initial loading.

The stiffness and strength degradation versus postelastic drift of joints is plotted in Figure 12. The entire degradation plot elevates the effectiveness of grid confinement in stiffness retention property. Figure $12 a$ shows that at 0.02 radian the specimen FEJ 3 shows nearly $50 \%$ degradation and at 0.04 radian it shows $70 \%$ degradation; however, at the same rotation the conventional specimens lost more than $60 \%$ and $80 \%$ stiffness respectively. The lesser rate of strength and stiffness degradation confirms the post-yield retention capacity offered by grid confinement.

\section{Energy dissipation and damping}

Figure 13 shows the comparison of cumulative energy dissipation and equivalent damping coefficient of joint specimens. The equivalent damping coefficient $\left(\xi_{\mathrm{eq}}\right)$ is calculated using the following eq. (3).

$$
\xi_{\mathrm{eq}}=\frac{E_{d}}{4 \pi E_{s o}}=\frac{1}{2 \pi}\left\{\frac{\text { Area }_{\text {loop }}}{F_{\max } D_{\max }}\right\},
$$

where area $_{\text {loop }}$ is the area enclosed by a hysteresis loop; $F_{\max }$ and $D_{\max }$ are the maximum load and displacement attained in a cycle.

The large loop area shows better grid confinement and dissipates higher energy compared to conventional specimens. The grid-confined specimens show higher rate of increase in dissipation of energy. The specimen FEJ 3 shows gradual enhancement in dissipation till failure which is $100 \%$ higher than conventional specimens. The combined effect of SFRC and grid further increases the dissipation capacity and shows $150 \%$ higher energy dissipation compared to conventional specimens. A similar trend has been observed with the damping coefficient. Figure $13 b$ shows the enhanced damping effect and confirms that the grid confinement possesses $40 \%$ higher damping before yield. The composite effect of steel fibre and grid confinement shows more than $45 \%$ higher damping after yield compared to conventional specimens. Also Figure $13 b$ shows no reduction in damping after peak, which authenticates the composite action in improving the energy dissipation under reverse cyclic loading.

\section{Moment-rotation behaviour}

The moment-plastic $(M-\theta)$ rotation relationships of joint specimens are calculated and compared with the recommended values of ASCE/SEI 41-06 and presented in Figure 14. The applied load and length of the beam and displacement are considered for the calculation of moment and rotation. The maximum moment is reached 

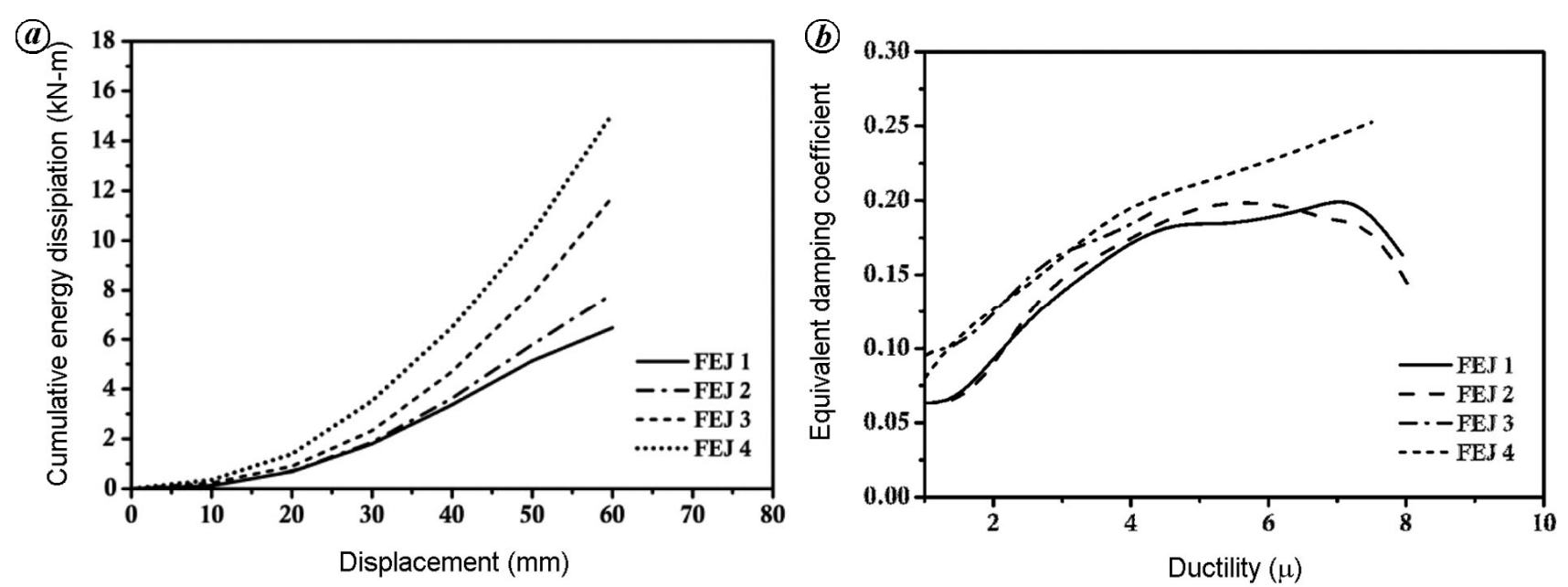

Figure 13. Energy dissipation behaviour of joint specimens. $\boldsymbol{a}$, Cumulative energy dissipation; $\boldsymbol{b}$, Equivalent damping coefficient.

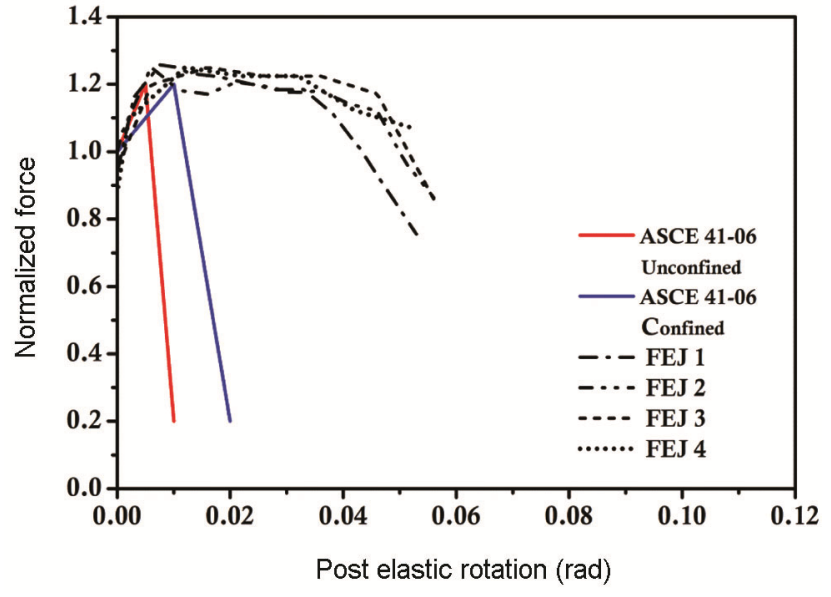

Figure 14. Moment-rotation behaviour of beam-column joints.

as the rotation reaches 0.01 radian and no significant loss of moment capacity is noticed while rotation varies from 0.01 to 0.04 radians. The geogrid-confined joint specimens offer better post-yield rotation capacity than the ASCE/SEI 41-06 recommended value in which the limit of linear elastic behaviour of conventional joints is 0.015 and the range of post-peak behaviour is 0.015 to 0.02 radians, as shown in Figure 14. It is evident that the geogrid confinement and SFRC significantly improve the $M-\theta$ capacity compared to conventional specimens. The presence of SFRC in geogrid-confined specimen elevates the post-peak rotation. The improved plastic rotation capacity with better moment retention authenticates the enhanced ductility of joint, which is really difficult to attain by conventional confinement.

\section{Crack formation mechanism and failure analysis}

The crack patterns of joint specimens at failure level are shown in Figure 15. The cracking behaviour of conven- tionally confined and geogrid-confined specimens with/ without steel fibre are different in terms of failure mechanism. In conventionally-confined specimens, flexure cracks were developed in the beam component in the initial stage of loading. As the deformation increased, crack formation was noticed in the beam column connection. The inadequate confinement in the joint and hinge region allows longitudinal beam rebar slip from the column. The vertical cracks can be seen in the column as shown in Figure $15 \mathrm{a}$. The top and bottom rebar slip creates large shear force which results in diagonal cracks on the joint region as shown in Figure $15 a$. The specimen FEJ 1 encounters early spalling of concrete in the beam hinge and has led the longitudinal reinforcement to buckle as shown in Figure $15 \mathrm{a}$. The reinforcement buckling is restricted in FEJ 2 because of closely spaced stirrups in the beam hinge region. The post-peak load degradation rate of specimen FEJ 2 is comparatively lesser than the specimen FEJ 1 due to the critical detailing in the joint zone. The concentration of primary cracking in the connection region of specimen FEJ 2 led the reinforcement to yield after $20 \mathrm{~mm}$ deflection and has failed at $60 \mathrm{~mm}$ deflection. The crack pattern of specimen with geogrid confinement is complex and different from the conventional specimens. Initially flexural cracks appeared in the beam hinge zone followed by flexural shear cracks near joint hinge zone as shown in Figure $15 c$. The observed flexural shear cracks were noticed between the grid and steel confinement. In the column portion, vertical and horizontal cracks were also noticed during severe loading. The domination of shear cracks in the joint zone is not as conventional specimens, which confirms the effective confinement of grid in resisting the shear. No spalling and rebar buckling were noticed with specimen FEJ 3 as evidenced in FEJ 1. The presence of SFRC in the joint zone problem along with grid confinement well addressed the formation of shear cracks, as 

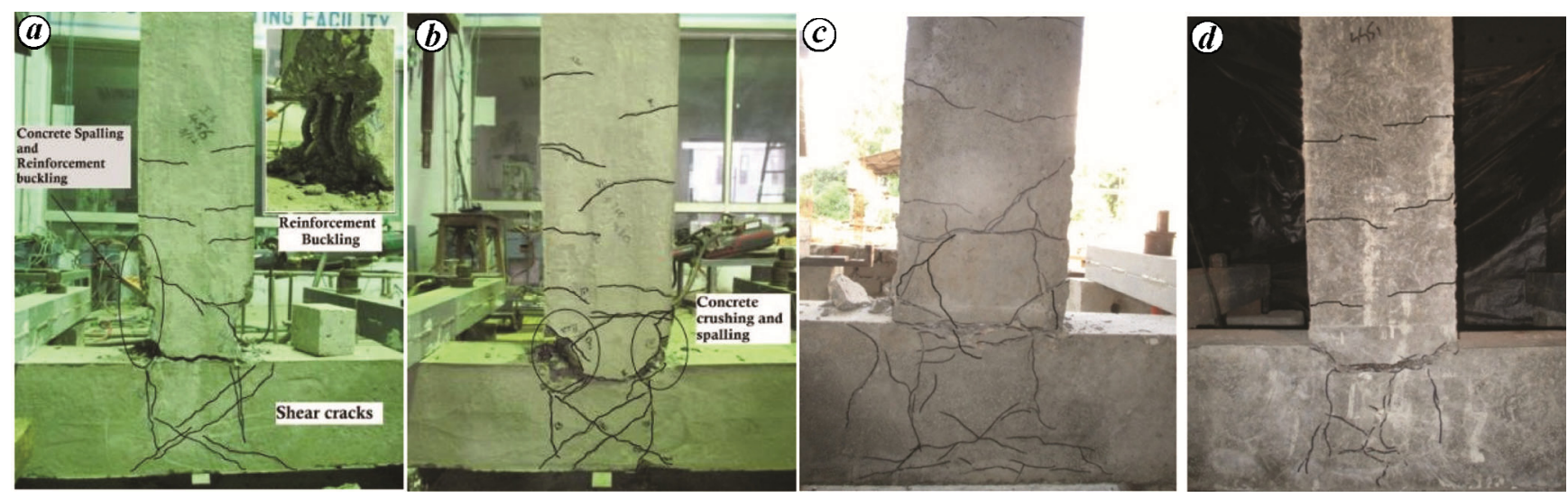

Figure 15. Crack patterns and failure modes of joint specimens. $\boldsymbol{a}$, FEJ 1; b, FEJ 2; $\boldsymbol{c}$, FEJ 3; $\boldsymbol{d}$, FEJ 4.

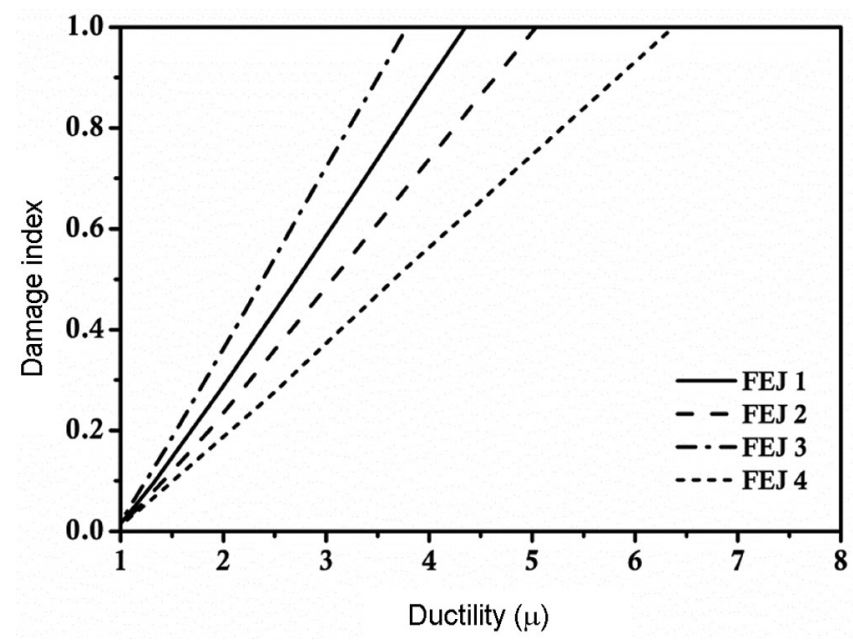

Figure 16. Damage index (DI) plot versus ductility of joint specimens.

shown in Figure $15 d$. The crack pattern of specimen FEJ 4 shows the absence of spalling of concrete in the beam hinge as well as in the connection zone as evidenced in FEJ 1 and FEJ 2. The cracks in the column portion evidence the restriction of longitudinal rebar slip from the joint due to improved bond strength of SFRC by restricting the crack formation. The post-yield behaviour of specimen FEJ 4 proves the shear resistance offered by the SFRC compared to other specimens.

\section{Damage index}

Modified Park and $\mathrm{Ang}^{34}$ damage index (DI) is used to examine the damage level and compare the relative performance of beam-column joint specimens with different configurations using eq. (4). Figure 8 shows the damage index versus ductility comparison. The ductility factor $(\mu)$, a measure of ductility of a structure, is defined as the ratio of $\Delta u$ and $\Delta y$, where $\Delta u$ and $\Delta y$ are the respective lateral deflections at the end of the post-elastic range, when the yield is first reached.

$$
\mathrm{DI}=\frac{\delta_{m}-\delta_{y}}{\delta_{u}-\delta_{y}}+\beta \int \frac{\mathrm{d} E}{F_{y} \delta_{u}},
$$

where $\delta_{m}$ is the maximum deflection $(\mathrm{mm}), \delta_{u}$ the ultimate deflection $(\mathrm{mm}), \delta_{y}$ the yield deflection $(\mathrm{mm}), \beta$ the strength degradation parameter, $\mathrm{d} E$ the dissipated energy, $F_{y}$ is the yield load.

Park and $\mathrm{Ang}^{34} \mathrm{DI}$ is used to estimate the damage tolerance capacity of joint specimens. The relative comparisons of DI of beam-column joint specimens with different confinements are plotted in Figure 16. It is observed that the DI values of all joint specimens in elastic region (I) show no damage. Both the conventional specimens reached moderate damage and other specimens showed slight damage level in yield to peak region (III) as shown in Figure 16. All beam-column joint specimens reached severe damage to collapse level during post-peak behaviour (IV). It is observed that the joint specimen FEJ 1 and FEJ 2 with conventional confinement have shown the advantage of ductile detailing of joint in improving the damage tolerance. The damage index plot shows that the geogrid-confined specimen FEJ 3 has lesser damage tolerance than conventional specimen FEJ 1. This is because of the early shear cracks in the joint region. However, the specimen with grid confinement with SFRC shows about two levels higher damage tolerance compared to control specimen FEJ 1.

\section{Conclusion}

The experimental investigation was conducted to examine the shear resistance capacity of RC beam and joints with geogrid confinement and steel fibres under static and cyclic loading. Some of the important observations of the study are summarized below. 
(1) The load deflection response of RC beams with grid confinement shows significant improvement in shear resistance and is further increased by adding small volume of steel fibres in concrete. There is about $50 \%$ enhancement in post-peak deflection with geogridconfined SFRC beam specimens than conventional beam specimens. The improved inelastic rotation allows to dissipate higher energy. The test results show that the composite effect of geogrid and SFRC improved the shear resistance capacity of a deficient beam specimen.

(2) It is observed that the rate of degradation in strength and stiffness of conventionally-confined beam specimens is higher than geogrid-confined specimens. The geogrid-confined beam specimens with and without steel fibres show better post-yield strength and stiffness retention.

(3) The failure pattern of beam specimens remains the same as conventional specimens but the reduction in deflection after shear crack formation shows the significance of grid confinement.

(4) The hysteretic behaviour shows the better shear strength and post-yield deformation capacity of geogridconfined specimen compared to conventionally confined specimen. The bond slippage failure of embedded longitudinal reinforcement in the joint region reduces due to the confining pressure of geogrid in the joint core. The improvement in ductility is remarkable with grid confinement and incorporation of steel fibre in concrete.

(5) The load deflection envelope curve shows the enhanced initial and yield stiffness capacity of geogridconfined joint specimens under cyclic loading. The composite action of grid and SFRC offers better postyield stiffness and strength retention than critically spaced conventional specimens.

(6) The hysteretic loop area of geogrid-confined specimens show about two times higher energy dissipation capacity compared to conventionally-confined specimens.

(7) The specified values of plastic rotation capacity for the linear elastic behaviour and post-peak behaviour of conventional and confined joints as per ASCE/SEI 41-06 are much lower compared to geogrid-confined beamcolumn joint. The rotation at failure of geogrid confinement specimens reaches up to 0.06 radian against 0.04 radian in conventional specimens. In addition, the rate of moment degradation of geogrid-confined specimen with SFRC considerably reduces compared to other specimens.

(8) The geogrid-confined beam-column joint specimens have more damage tolerance capacity. The observed damage index and mode of failure prove that the geogrid confinement can resist up to peak load without severe damage in the joint region. It is understood that the geogrid-confined specimen with SFRC has undergone two times lower damage compared to conventional specimens with and without ductile detailing at the same range of displacement.
(9) This study is mainly focused on the shear resistance behaviour of geogrid confinement in the plastic hinge zones of RC beams and beam-column joints. The experimental results authenticate the influence of geogrid and steel fibre in increasing the shear resistance and show improvement in the damage tolerance capacity.

1. Parra-Montesinos, G. J., Shear strength of beams with deformed steel fibres. Concr. Int., 2006, 28(11), 57.

2. Gençoğlu, M. and Eren, I., An experimental study on the effect of steel fiber reinforced concrete on the behavior of the exterior beam-column joints subjected to reversal cyclic loading. Turkish J. Eng. Env. Sci., 2002, 26(6), 493-502.

3. Susetyo, J., Gauvreau, P. and Vecchio, F. J., Effectiveness of steel fibres as crack controllers, assessment using shear panel tests. In Fracture Mechanics of Concrete and Concrete Structures-High Performance, Fiber Reinforced Concrete, Special Loadings and Structural Applications (eds Oh, B. H. et al.), Proc. FraMCoS-7, 2010, pp. 1478-1486.

4. Venkateshwaran, A. and Tan, K. H., Load-carrying capacity of steel fibre reinforced concrete beams at large deflections. Struct. Conc., 2017; doi:10.1002/suco.201700129.

5. American Concrete Institute-ACI Committee, 1996. ACI 544.1 R96, state-of-the-art report on fibre reinforced concrete. ACI Committee, Detroit.

6. Tiberti, G., Germano, F., Mudadu, A. and Plizzari, G. A., An overview of the flexural post-cracking behaviour of steel fibre reinforced concrete. Struct. Concr., 2018, 19(3), 695-718; doi:10. 1002/suco.201700068.

7. Chidambaram, R. S. and Agarwal, P., Flexural and shear behaviour of geogrid confined RC beams with steel fibre reinforced concrete. Constr. Build. Mater., 2015, 78, 271-280.

8. Hwang, S. J., Lee, H. J., Liao, T. F., Wang, K. C. and Tsai, H. H., Role of hoops on shear strength of reinforced concrete beamcolumn joints. ACI Struct. J., 2005, 102(3), 445-453.

9. Lee, J. Y., Kim, J. Y. and Oh, G. J., Strength deterioration of reinforced concrete beam-column joints subjected to cyclic loading. Eng. Struct., 2009, 31(9), 2070-2085.

10. Costa, R., Providência, P. and Dias, A., Component-based reinforced concrete beam-column joint model. Struct. Concr., 2017, 18(1), 164-176.

11. Alameddine, F. and Ehsani, M. R., High-strength RC connections subjected to inelastic cyclic loading. J. Struct. Eng., 1991, 117(3), 829-850.

12. Dadi, V. S. K. and Agarwal, P., Influence of reinforcement characteristics on non-linear performance evaluation of confined beam-column joints under cyclic loading. Adv. Civil Eng. Mater., 2013, 2(1), 201-217.

13. Murty, C. V. R., Rai, D. C., Bajpai, K. K. and Jain, S. K., Effectiveness of reinforcement details in exterior reinforced concrete beam-column joints for earthquake resistance. ACI Struct. J., 2003, 100(2), 149-156.

14. Dadi, V. V. S. S. K. and Agarwal, P., Cyclic performance evaluation of unconfined and confined beam-column joint specimens with different type of reinforcing characteristics as per ASCE/SEI 41-06. Aust. J. Struct. Eng., 2013, 14(3), 258-272.

15. Kotsovou, G. and Mouzakis, H., Seismic design of RC external beam-column joints. Bull. Earthq. Eng., 2002, 10(2), 645677.

16. Jiuru, T., Chaobin, H., Kaijian, Y. and Yongcheng, Y., Seismic behaviour and shear strength of framed joint using steel-fibre reinforced concrete. J. Struct. Eng., 1992, 118(2), 341-358.

17. Campione, G., La Mendola, L. and Papia, M., Shear strength of steel fibre reinforced concrete beams with stirrups. Struct. Eng. Mech., 2006, 24(1), 107-136. 
18. Ganesan, N., Indira, P. V. and Abraham, R., Steel fibre reinforced high performance concrete beam-column joints subjected to cyclic loading. ISET J. Earthq. Technol., 2007, 44(3-4), 445-456.

19. Somma, G., Shear strength of fibre reinforced concrete beamcolumn joints under seismic loading, In Proceedings of 14th World Conference on Earthquake Engineering, Beijing, China, 12-17 October 2008.

20. Narayanan, R. and Darwish, I. Y. S., Use of steel fibres as shear reinforcement. ACI Struct. J., 1997, 84(3), 216-227.

21. Li, V. C., Ward, R. and Hmaza, A. M., Steel and synthetic fibres as shear reinforcement. ACI Mater. J., 1992, 89(5), 499508.

22. Dinh, H. H., Parra-Montesinos, G. J. and Wight, J. K., Shear behaviour of steel fibre-reinforced concrete beams without stirrup reinforcement. ACI Struct. J., 2010, 107(5), 597-606.

23. Daviau-Desnoyers, D., Charron, J. P., Massicotte, B., Rossi, P. and Tailhan, J. L., Influence of reinforcement type on macrocrack propagation under sustained loading in steel fibre-reinforced concrete. Struct. Concr., 2016, 17(5), 736-746.

24. Adebar, P., Mindess, S., St-Pierre, D. and Olund, B., Shear tests of fibre concrete beams without stirrups. ACI Struct. J., 1997, 94(1), 68-76.

25. Kwak, Y. K., Eberhard, M. O., Kim, W. S. and Kim, J., Shear strength of steel fibre-reinforced concrete beams without stirrups. ACI Struct. J., 2002, 99(4), 530-538.

26. Naaman, A. E., SIFCON - tailored properties for structural performance. In High Performance Fiber Reinforced Cement Composites, World Scientific, 2008, pp. 18-38.

27. Altun, F., Haktanir, T. and Ari, K., Effects of steel fibre addition on mechanical properties of concrete and RC beams. Construct. Build. Mater., 2007, 21(3), 654-661.
28. Boulekbache, B., Hamrat, M., Chemrouk, M. and Amziane, S., Flow ability of fibre-reinforced concrete and its effect on the mechanical properties of the material. Constr. Build. Mater., 2010, 24(9), 1664-1671.

29. Tang, X., Kim, S. and Chehab, G. R., Laboratory study of geogrid reinforcement in Portland cement concrete. In RILEM International Conference on Cracking Pavements, Chicago, Illinois, 1618 June 2008.

30. El Meski, F. and Chehab, G. R., Flexural behaviour of concrete beams reinforced with different types of geogrids. J. Mater. Civil Eng., 2013, 26(8).

31. Chidambaram, R. S. and Agarwal, P., The confining effect of geogrid on the mechanical properties of concrete specimens with steel fibre under compression and flexure. Constr. Build. Mater., 2013, 71, 628-637.

32. Sivakamasundari, S., Joshua Daniel, A. and Arun Kumar, Study on flexural behaviour of steel fiber RC beams confined with biaxial geo-grid. Proc. Engg., 2017, 173, 1431-1438.

33. Yalciner, H., Kumbasaroglu, A., Ertuc, I. and Turan, A. I., Confinement effect of geo-grid and conventional shear reinforcement bars subjected to corrosion. Structures, 2018, 13, 139-152.

34. Park, Y. J., Ang, A. H. and Wen, Y. K., Damage-limiting aseismic design of buildings. Earthq. Spectra, 1987, 3(1), 1-26.

ACKNOWLEDGEMENT. We thank the support of STRATA GeoSystems for and providing geogrid for this research work.

Received 13 April 2018; revised accepted 29 April 2019

doi: $10.18520 / \mathrm{cs} / \mathrm{v} 117 / \mathrm{i} 2 / 260-271$ 